\title{
Diversité biologique et caractérisation de l'activité de maraîchage sur le site de Grand-Popo au Sud Bénin
}

\author{
Arlette ADJATIN ${ }^{1 *}$, Zaki BONOU-GBO ${ }^{1}$, Armel BOCO $^{1}$, \\ Hounankpon YEDOMONHAN ${ }^{2}$ et Alexandre DANSI ${ }^{1}$ \\ ${ }^{I}$ Ecole Nationale Supérieure des Biosciences et Biotechnologies appliquées, Université Nationale des Sciences, \\ Technologies Ingénierie et Mathématiques, BP 14 Dassa, Bénin. \\ ${ }^{2}$ Faculté des Sciences et Techniques, Université d'Abomey-Calavi, BP 526 Cotonou, Bénin. \\ *Auteur correspondant ; E-mail: aarlette2000@yahoo.fr, Tel : (00229) 97440798
}

\section{RESUME}

Le maraîchage revêt une importante source alimentaire et constitue l'une des activités les plus génératrices de revenus au Bénin. La présente étude a pour objectif de contribuer à la sécurité alimentaire à travers une meilleure connaissance des cultures maraîchères de même que les difficultés liées à leur production. Les données ont été collectées à travers des enquêtes individuelles auprès de trente-deux (32) maraîchers installés sur le site maraîcher de Grand-Popo. Au total, neuf (9) espèces maraîchères ont été recensées auprès des maraichers provenant de diverses origines. Parmi ces différentes espèces l'oignon constitue la principale culture, ensuite viennent la tomate, la grande morelle, la carotte, la laitue, la betterave, le concombre, l'aubergine et le piment. Les espèces recensées se répartissent en quatre espèces de légumes-fruits (44,45\% des espèces), en deux espèces de légumes-feuilles $(22,22 \%)$ et légumes-racines $(22,22 \%)$ et en une espèce de légume-bulbe $(11,11 \%)$. La plupart des exploitations sont confrontées à dix contraintes parmi lesquelles les plus importantes sont les attaques des insectes (46,08\% de réponses), les maladies fongiques (25,35\% de réponses) et les nématodes (13,08\% de réponses). Quatorze (14) pesticides chimiques dont les insecticides (56,25\% de réponses), des fongicides (21\% de réponses), des nématicides (17,50\% de réponses) et des acaricides $(5,25 \%$ de réponses) ont été répertoriés. Pour une meilleure connaissance des activités de maraîchages au Bénin, il est nécessaire d'étendre l'étude sur tous les sites maraîchers en vue de disposer d'une base complète de données sur les espèces cultivées en maraîchage

(C) 2019 International Formulae Group. All rights reserved

Mots clés : Culture maraîchère, diversité, contrainte, pratiques agricoles, Bénin.

\section{Biological diversity and characterization of market gardening activity at the Grand-Popo site in southern Benin}

\begin{abstract}
Market gardening is an important food source and one of the most income-generating activities in Benin. The present study aims to contribute to food security through a better knowledge of market gardening as
\end{abstract}


well as the difficulties related to their production. The data were collected through individual surveys of thirtytwo (32) market gardeners installed on the Grand-Popo market garden site. A total of nine (9) vegetable species have been identified with market gardeners from various origins. Among these different species, onion is the main crop, followed by tomato, nightshade, carrot, lettuce, beet, cucumber, eggplant and pepper. The species listed fall into four species of fruiting vegetables (44.45\% of the species), two species of leafy vegetables $(22.22 \%)$, root vegetables $(22.22 \%)$ and one species of bulb vegetable $(11.11 \%)$. Most farms face ten constraints among which the most important are insect attacks (46.08\% of responses), fungal diseases $(25.35 \%$ of responses) and nematodes (13.08\% of responses). Fourteen (14) chemical pesticides including insecticides (56.25\% response), fungicides (21\% response), nematicides (17.50\% response) and acaricides $(5.25 \%$ response) have been listed. For a better knowledge of market gardening activities in Benin, it will be necessary to extend the study to all market gardening sites in order to have a complete database of species cultivated in market gardening.

(C) 2019 International Formulae Group. All rights reserved

Keywords: Vegetable species, diversity, constraint, agricultural practices, Benin.

\section{INTRODUCTION}

L'agriculture est l'un des principaux secteurs d'activités qui contribue au développement socioéconomique des populations. Elle emploie plus de $40 \%$ de la population active dans le monde dont plus de $52 \%$ en Afrique (Koc et al., 2006 ; Yarou et al., 2017). Dans ce secteur, le maraichage occupe une place importante pour l'alimentation humaine et répond de façon efficace à la demande alimentaire urbaine (FAO, 2012). Les cultures maraichères représentent une source importante alimentaire variée qui complète bien les besoins alimentaires des populations dont l'alimentation de base est constituée essentiellement de glucides, principaux éléments énergétiques (Yolou et al., 2015). L'agriculture maraîchère est marquée par une diversification spécifique et variétale et constitue une activité qui se rencontre dans presque toutes les régions du pays, mais son ampleur varie très considérablement entre producteurs et entre régions (Koc et al., 2006).

Au Bénin, la production maraîchère est caractérisée par une diversification des espèces cultivées. Les revenus générés par cette activité maraîchère permettent à plusieurs centaines de familles de subvenir à leurs besoins quotidiens (Houssou, 2014). En effet, l'ensemble des aires emblavées pour la production maraîchère a connu de 1999 à 2003 un accroissement de 18\%. Cependant, elle est confrontée à d'énormes difficultés dont les attaques dues aux insectes et pathologies affectant le rendement qualitatif et quantitatif des produits (Kanda et al., 2014 ; Mondédji et al., 2015). Des produits chimiques qui ne sont pas sans conséquence sur la santé des consommateurs et parfois des producteurs sont utilisés par ces maraîchers pour pallier ces contraintes (Kanda et al., 2009 ; Atidegla et al., 2011). Selon Pesticide Action Network (PAN-Africa, 2005), l'apport de quantités excessives ou inadaptées, sans respect des délais de carence, est fréquent dans les pays en développement. De plus, les produits maraîchers n'assurent pas un approvisionnement régulier permettant de combler la demande dans les zones de consommation (Tiamiyou et Sodjinou, 2003).

Par ailleurs, plusieurs études ont porté sur les conséquences des changements climatiques sur la production maraîchère (Atidegla et al., 2017), la productivité (Tchabi et al., 2012), les produits chimiques (Agueh et al., 2015 ; Chouti et al., 2018) et la filière maraîchère (Agossou et al. 2001). De nombreuses potentialités (utilisation des semences à cycle court, agriculture de contre saison, etc.) existent pour pallier les contraintes de production maraîchère. Il est 
nécessaire d'accompagner les producteurs dans le renforcement de leurs capacités en définissant des bases scientifiques permettant de maintenir, d'améliorer et de conserver de manière dynamique la diversité des espèces maraîchères en tenant compte aussi bien du rendement que de leur adaptation aux nouvelles conditions climatiques. Ainsi le présent travail réalisé sur le site de GrandPopo est une contribution à l'amélioration de la production des cultures maraîchères au Bénin. Il vise à analyser l'activité de maraîchage à travers l'inventaire des espèces végétales cultivées et l'identification des différentes contraintes liées leur production, leur importance économique pour les maraîchers de même que leurs principales pratiques culturales.

\section{MATERIEL ET METHODES}

\section{Présentation du milieu d'étude}

La ville de Grand-Popo est située dans la région Sud-Ouest du Bénin. C'est l'une des communes du département du Mono qui s'étend sur une superficie de $289 \mathrm{~km}^{2}$, soit $7,2 \%$ de l'ensemble du département (Figure 1). Sa densité moyenne est de 140 habitants $/ \mathrm{km}^{2}$. Elle est limitée au Nord par les Communes d'Athiémé, de Comé et de Houéyogbé, au Sud par l'Océan Atlantique, au Sud-Ouest par les Communes de Ouidah et de Kpomassè et à l'Ouest par la République du Togo. Plus de 62\% du territoire est constitué de plaines inondables, de bas-fonds propices et de façade maritime propice à la culture maraîchère. Le climat est subéquatorial avec une pluviométrie annuelle moyenne qui varie de 900 à $1500 \mathrm{~mm}$. La température moyenne annuelle y est de $26,5^{\circ} \mathrm{C}$ et l'humidité relative de $75 \%$ en moyenne par an avec une insolation moyenne annuelle de 2290 heures (Adomou, 2005).

\section{Collecte des données}

Cette étude s'est basée sur des enquêtes individuelles auprès de trente-deux (32) maraîchers installés dans la zone maritime et présents pendant la période d'enquête. Sur chaque site d'exploitation, le questionnaire d'enquête a été adressé au chef d'exploitation ou à son représentant selon Kanda et al. (2014). Les différentes données collectées ont concerné les caractéristiques socio-démographiques (sexe, origine, ethnie d'appartenance et la taille de l'exploitation), les principales espèces cultivées, les différents groupes des ravageurs et les principales pathologies des légumes, les périodes de fortes attaques et les produits utilisés pour les traitements phytosanitaires. Les pratiques culturales incluant les différents systèmes de cultures, les périodes de culture, les modes de fertilisation, les prix de vente et les contraintes de production relatives aux cultures maraichères ont été également collectées. Les données d'enquête ont été complétées par des observations directes des cultures sur les planches dont les noms scientifiques ont été déterminés suivant la nomenclature de Akoègninou et al. (2006).

\section{Traitement statistique des données}

Le logiciel Excel a été utilisé pour le traitement des données collectées et a permis de calculer les moyennes et les fréquences. Les résultats sont présentés sous forme de tableaux et figures. Un dendrogramme des maraîchers a été construit en fonction de leur origine, les différentes espèces maraîchères produites, le nombre de ses spéculations de même que la culture prioritaire avec le logiciel Minitab afin de déterminer la typologie des maraîchers. 


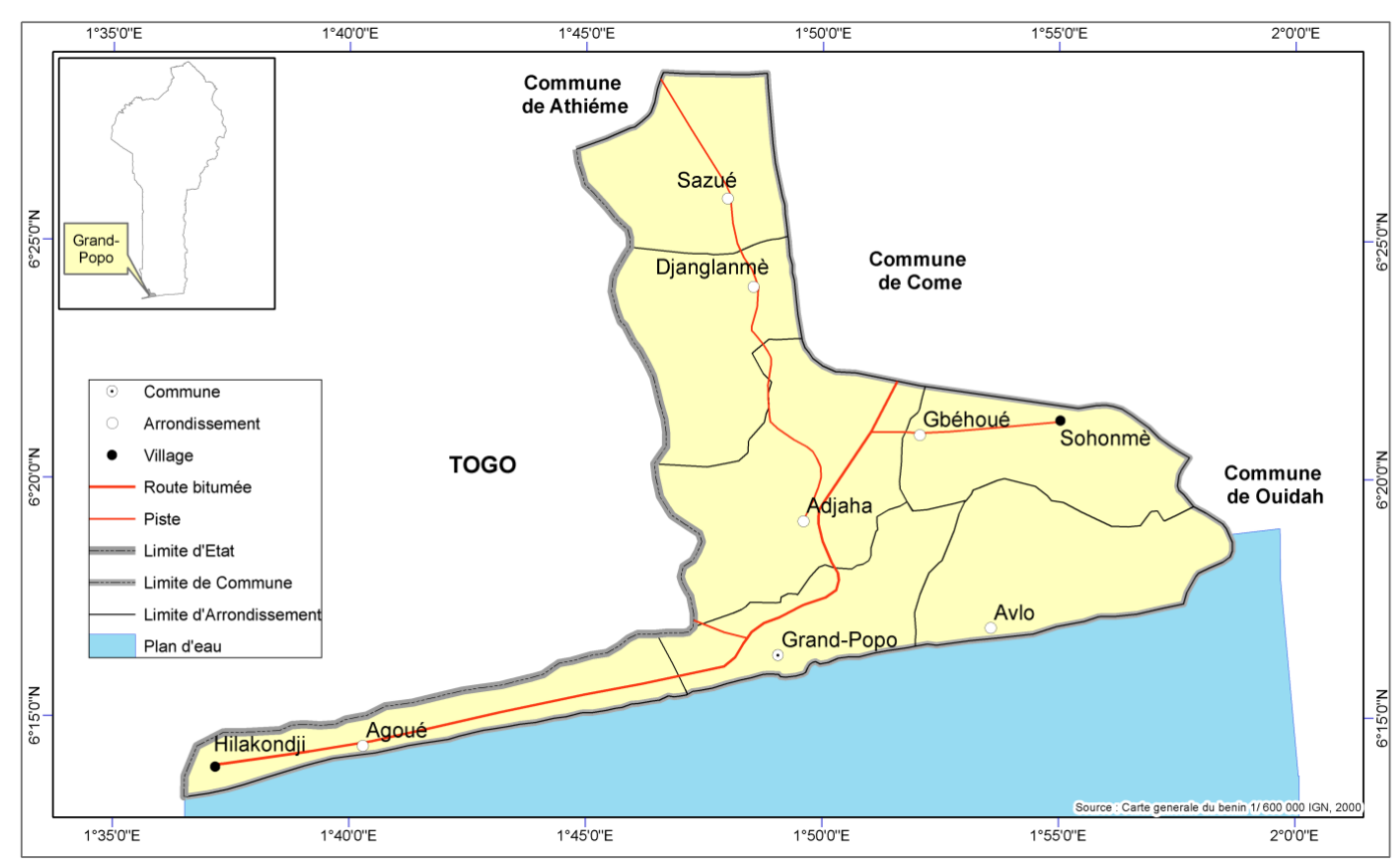

Figure 1 : Carte montrant la zone d'étude.

\section{RESULTATS \\ Caractéristiques sociodémographiques des producteurs interrogés}

Différentes origines incluant des étrangers caractérisent les maraîchers interviewés dans la zone d'étude. Parmi ceuxci, la majorité $(65,63 \%)$ est de Grand-Popo suivi de ceux venant du Togo $(15,63 \%)$, de Lokossa $(9,36 \%)$, du Ghana $(6,25 \%)$ et du Niger $(3,13 \%)$. Ces maraîchers rencontrés sur le site appartiennent principalement à quatre groupes ethniques dont le Mina, Ouatchi, Xwla et Zarman respectivement dans les proportions de $84,38 \% ; 6,25 \% ; 6,25 \%$ et $3,12 \%$. La plupart des exploitations (70\%) sont dirigées par des hommes. La main d'œuvre utilisée est soit familiale soit salariale permanente ou salariale occasionnelle avec une rémunération hebdomadaire ou mensuelle variant selon l'ancienneté et le type de travail et compris entre $15000 \mathrm{Fcfa}$ et $30000 \mathrm{Fcfa}$ le mois. Suivant l'importance de l'exploitation, la taille de la main d'œuvre peut atteindre jusqu'à 15 personnes.

\section{Importance économique des cultures maraichères à Grand-Popo}

Diverses unités de mesure sont utilisées pour la commercialisation de ces produits maraichers. Il s'agit de la planche pour l'oignon, la carotte et la grande morelle, le panier pour la tomate; le plant pour la laitue et la betterave; le sceau pour le piment; la quarantaine pour l'aubergine et le concombre (Tableau 1). Les prix de vente varient en fonction des saisons et des cultures. Ainsi le prix de vente de la carotte varie de $27500 \mathrm{~F}$ à 52000 FCFA la plante tandis que celui de l'oignon varie de $16365 \mathrm{~F}$ à 35192 FCFA la planche. La même tendance a été observée au niveau des autres spéculations qui connaissent une variation de prix au cours de l'année (Tableau 1).

\section{Principales contraintes de production des} cultures maraîchères

$\mathrm{Au}$ total, dix contraintes ont été signalées par les maraîchers dans la zone d'étude (Figure 2). Les principales contraintes énumérées par les maraichers interviewés et qui sont aussi bien d'ordre abiotique que 
biotique, sont les attaques des insectes (46,48\% de réponses) à savoir les chenilles, les mouches blanches, les mouches de fruits; suivies des maladies fongiques dues aux champignons $(25.35 \%$ de réponses) et des nématodes ( $14.08 \%$ de réponses). D'autres contraintes telles que la rouille, l'attaque des oiseaux, les virus, les excès de pluies et les mauvaises herbes constituent également des contraintes non négligeables liées à la culture maraichère.

Aussi la présence ou non et l'importance de chacune de ces contraintes varient d'une culture à une autre (Tableau 2). Leur hiérarchisation permet de classer les attaques des insectes en première position $(100 \%)$ viennent ensuite, les nématodes et l'excès d'eau correspondant respectivement à $55,55 \%$ et $33,33 \%$ des cultures attaquées.

\section{Diversité des cultures maraichères dans la zone d'étude}

Neuf (09) espèces maraîchères appartenant à sept (07) différentes familles ont été recensées (Tableau 3). Il s'agit de l'oignon (Allium cepa L., Alliaceae), la tomate (Lycopersicum esculentum Mill., Solanaceae), la grande morelle (Solanum macrocarpum L., Solanaceae), le piment (Capsicum frutescens. L., Solanaceae), et les légumes exotiques tels que la carotte (Daucus carota L. Apiaceae), le concombre (Cucumis sativus $\mathrm{L}$. Cucurbitacea), la betterave (Beta vulgaris L., Amaranthaceae), l'aubergine (Solanum melongena L. Solanaceae) et la laitue (Lactuca sativa $\mathrm{L}$. Asteraceae). La famille la plus représentée est celle des Solanaceae repartie en trois genres avec quatre espèces. Les espèces récensées se répartissent en quatre espèces de légumes-fruits $(44,45 \%$ des espèces), en deux espèces de légumes-feuilles $(22,22 \%)$ et légumes-racines $(22,22 \%)$ et en une espèce de légume-bulbe $(11,11 \%)$.

L'analyse de la distribution et de l'étendue des espèces maraîchères recensées sur le site de Grand-Popo permet de distinguer quatre catégories de spéculations:

- les espèces maraîchères cultivées sur de grandes superficies et par beaucoup de maraîchers; il s'agit de l'oignon et de tomate

- les espèces maraîchères cultivées sur de grandes superficies et par peu de maraîchers ; ce sont la grande morelle et la carotte

- les espèces maraîchères cultivées sur de peu de superficies et par beaucoup de maraîchers : il s'agit de concombre

- les espèces maraîchères cultivées sur de petites superficies par peu de producteurs ; cette catégorie concerne la betterave, l'aubergine africaine, le lait et le piment.

En somme, dans cette zone maraîchère, la production d'oignon occupe plus de 40,63\% des maraichers interviewés à cause de sa grande rentabilité et surtout pendant la saison des pluies. Ensuite viennent la tomate, la morelle et la carotte respectivement dans les proportions de $31,25 \% ; 10,94 \%$ et $7,81 \%$. Les autres cultures telles que le concombre, la laitue, l'aubergine, la betterave et le piment apparaissent dans de faibles proportions respectives de $3,13 \% ; 1,56 \% ; 1,56 \%$; $1,56 \% ; 1,56 \%$ (Figure 3 ). Compte tenu des moyens financiers et de l'accès à la terre, le nombre de cultures produites varie de 1 à 5 suivant les producteurs (Figure 4). La monoculture étant majoritairement pratiquée avec un taux de $37,5 \%$ de producteurs suivi $34,38 \%$ de producteurs qui associent deux (2) cultures. Très peu de producteurs $(3,13 \%)$ associent 5 cultures sur la parcelle emblavée.

\section{Typologie des maraîchers interviewés dans la zone d'étude}

Trois (03) différentes classes de maraîchers ont été obtenues en se basant sur le type de cultures, le nombre de spéculations et l'origine des enquêtés (Figure 5). La première classe (C1) est constituée de quatorze (14) maraîchers nationaux cultivant beaucoup d'espèces mais avec une prédominance de la culture de l'oignon. L'oignon représente la seule et unique culture des maraichers de la deuxième classe constituée de douze (12) maraîchers qui sont aussi bien nationaux qu'internationaux. Enfin, dans la troisième classe, se trouve six (06) maraichers de différentes nationalités produisant plusieurs 
espèces essentiellement que sont la tomate et des légumes exotiques telles que la carotte, la laitue, la betterave et le concombre.

\section{Origine des semences et variétés utilisées}

Les semences utilisées par les producteurs sont fournies soit par les structures informelles $(27,69 \%$ de réponses) telles que les vendeurs ambulants venant des pays voisins (Niger et Nigéria) et parfois de Malanville essentiellement pour les semences de l'oignon et de morelle; soit par les structures formelles $(41,53 \%$ de réponses) telles que les supermarchés, les boutiques de vente des produits maraichers. Certains maraichers $(30,58 \%$ de réponses) produisent eux-mêmes leurs semences (Figure 6). Les semences acquises auprès des structures formelles sont en général des semences améliorées des cultures de la tomate, la carotte, la laitue, l'aubergine, la betterave, le piment et le concombre.

Dans le cadre de la production de l'oignon, la variété la plus utilisée est la variété locale (oignon violet) dont le cycle de production varie entre 4 et 5 mois. Ces semences sont vendues par les Haoussa et Peulhs venant essentiellement de Malanville et pays voisins comme le Niger et le Nigéria. Les variétés de tomate utilisées sont les variétés améliorées comme Pectomech qui est la variété de saison et Mongal qui est la variété de contre saison. Ces variétés de tomate ont un cycle de production de 3 mois. Les variétés de morelle les plus cultivées sont la petite morelle et la grande morelle avec un cycle de production qui dure 75 jours. Avec un cycle de production de 3 mois, la variété de carotte cultivée par ces maraichers est l'hybride.

\section{Pratiques culturales et phytosanitaire sur le site maraicher de Grand-Popo}

Pour la plupart des cultures maraîchères recensées $(77,7 \%)$, la production démarre par une pépinière qui dure 2 à 6 semaines suivant les cultures (Tableau 4). La durée la plus courte ( 2 semaines) est observée au niveau de la laitue et la durée la plus longue (6 semaines) concerne la culture des oignons. Une semaine après repiquage, la fertilisation organique constituée de la bouse de vache utilisée comme fumure organique pour toutes les cultures maraîchères. Contrairement à la fertilisation organique, la fertilisation chimique (la potasse ou l'ammoniac mélangé avec le NPK) est appliquée deux (2) à quatre (4) au cours du cycle de production de l'espèce. Dans ce système, les produits chimiques sont fortement régulièrement utilisés par les maraîchers. En effet le traitement phytosanitaire s'effectue au moins une (1) par semaine et parfois plus selon le degré d'atteinte des ravageurs ou des maladies. Seule la production de piment ne nécessite pas un traitement phytosanitaire hebdomadaire mais plutôt un traitement mensuel.

Les produits phytosanitaires utilisés par les maraichers pour lutter contre les ravageurs et les maladies sont essentiellement de nature chimique. Au total, quatorze (14) produits chimiques ont été répertoriés au cours de cette enquête. Il s'agit des insecticides (Laser, Duban, Attack, Super gros, K-optimal, Lambda Super 2.5 EC et Cypercal) qui sont les plus nombreux représentant $56,25 \%$ de réponses; des fongicides (Topsin, Bendazim et Godensine,) qui correspondent à $21 \%$ de réponses, des nématicides (Nématue et Carbofuran) avec $17,50 \%$ de réponses et seulement $5,25 \%$ de réponses représentant les acaricides (Acarius et Coecid). Les conséquences inhérentes à l'emploi de ces produits ne sont plus à démontrer. Par ailleurs, certains pesticides utilisés comme c'est le cas par exemple de Dusban, sont des insecticides de coton à forte toxicité et prohibée pour les cultures vivrières. 
Tableau 1 : Unité de vente et prix correspondants de chaque produit.

\begin{tabular}{lllllll}
\hline \multirow{2}{*}{ Cultures } & Noms scientifiques & $\begin{array}{l}\text { Unité } \\
\text { vente }\end{array}$ & $\begin{array}{l}\text { de Prix bas Prix élevé Prix moyen } \\
\text { (FCFA) }\end{array}$ & $\begin{array}{l}\text { \%CFA) } \\
\text { (FCFA) }\end{array}$ & d'augmentation \\
\hline Oignon & Allium cepa & Planche & 16365 & 35192 & 25778 & $115,04 \%$ \\
Tomate & Lycopersicon esculentum & Panier & 5700 & 13600 & 9650 & $138,59 \%$ \\
Morelle & Solanum macrocarpon & Planche & 4125 & 11375 & 7750 & $175,75 \%$ \\
Carotte & Daucus carota & Planche & 27500 & 52000 & 40000 & $89,09 \%$ \\
Concombre & Cucumis sativus & Quarantaine & 1500 & 4000 & 2750 & 166,66 \\
Laitue & Lactuca sativa & Pied & 25 & 75 & 50 & $200 \%$ \\
Betterave & Beta vulgaris & Pied & 25 & 75 & 50 & $200 \%$ \\
Piment & Capsicum frutescens & Sceau & 4000 & 7000 & 5500 & $75 \%$ \\
Aubergine & Solanum melongena & Quarantaine & 5000 & 7000 & 6000 & $40 \%$ \\
\hline
\end{tabular}

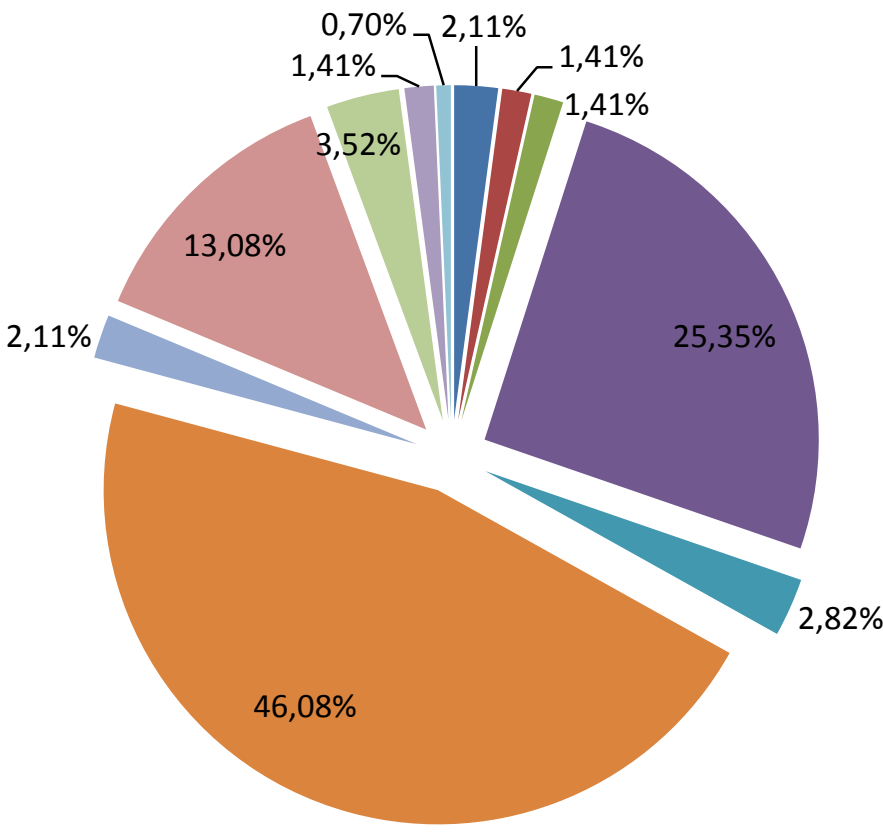

Acariens

Anthracnose

Bactéries

- Champignons

Excès d'eau

Insectes

Mauvaises herbes

Nématodes

Attaque des oiseaux

Rouille

Virus

Figure 2 : Fréquence des contraintes de production des cultures maraichères dans la zone d'étude. 
A. ADJATIN et al. /Int. J. Biol. Chem. Sci. 13(6): 2750-2764, 2019

Tableau 2 : Identification, hiérarchisation des contraintes pour chaque culture

\begin{tabular}{|c|c|c|c|c|c|c|c|c|c|c|c|}
\hline Contraintes & Oignon & Tomate & Morelle & Concombre & Laitue & Aubergine & Piment & Betterave & Carotte & NCA & PCA (\%) \\
\hline Acariens & & 6 & 2 & & & & & & & 2 & 22,22 \\
\hline Champignons & & 2 & & & & & 2 & & & 2 & 22,22 \\
\hline Excès de pluies & 4 & & 2 & & & & & & 2 & 3 & 33,33 \\
\hline Bactéries & & 6 & & & & 2 & & & & 2 & 22,22 \\
\hline Mauvaises herbes & 3 & 6 & & & & & & & & 2 & 22,22 \\
\hline Nématodes & & 3 & 1 & 2 & & 3 & & 2 & & 5 & 55,55 \\
\hline Virus & & 6 & & & & & 3 & & & 2 & 22,22 \\
\hline Rouille & & 5 & & & & & & & & 1 & 11,11 \\
\hline Anthracnose & 2 & & & & & & & & & 1 & 11,11 \\
\hline Oiseaux & & 4 & & & & & & & & 1 & 11,11 \\
\hline Insectes & 1 & 1 & 1 & 1 & 1 & 1 & 1 & 1 & 1 & 9 & 100 \\
\hline
\end{tabular}

NCA $=$ Nombre de cultures attaquées $;$ PCA= Pourcentage de cultures attaquées

Tableau 3 : Espèces maraîchers recensées et leur distribution et étendue à travers le site de Grand-Popo,

\begin{tabular}{|c|c|c|c|c|c|}
\hline $\mathbf{N}^{\circ}$ & Culture & Noms scientifiques & Familles & Organe cnsommé & Distribution et Etendue \\
\hline 1 & Aubergine & Solanum melongena $\mathrm{L}$. & Solanaceae & Fruit & $(--)$ \\
\hline 2 & Betterave & Beta vulgaris $\mathrm{L}$. & Amaranthaceae & Racine & $(--)$ \\
\hline 3 & Carotte & Daucus carota $\mathrm{L}$. & Apiaceae & Racine & $(+-)$ \\
\hline 4 & Concombre & Cucumis sativus L. & Cucurbitacea & Fruit & $(-+)$ \\
\hline 5 & Laitue & Lactuca sativa $\mathrm{L}$. & Asteraceae & Feuille & $(-+)$ \\
\hline 6 & Morelle & Solanum macrocarpum L., & Solanaceae & Feuille & $(+-)$ \\
\hline 7 & Oignon & Allium cepa $\mathrm{L}$. & Alliaceae & Bulbe & $(++)$ \\
\hline \multirow[t]{2}{*}{8} & Piment & Capsicum frutescens. L., & Solanaceae & Fruit & $(--)$ \\
\hline & Tomate & Lycopersicum esculentum Mill. & Solanaceae & Fruit & $(++)$ \\
\hline
\end{tabular}




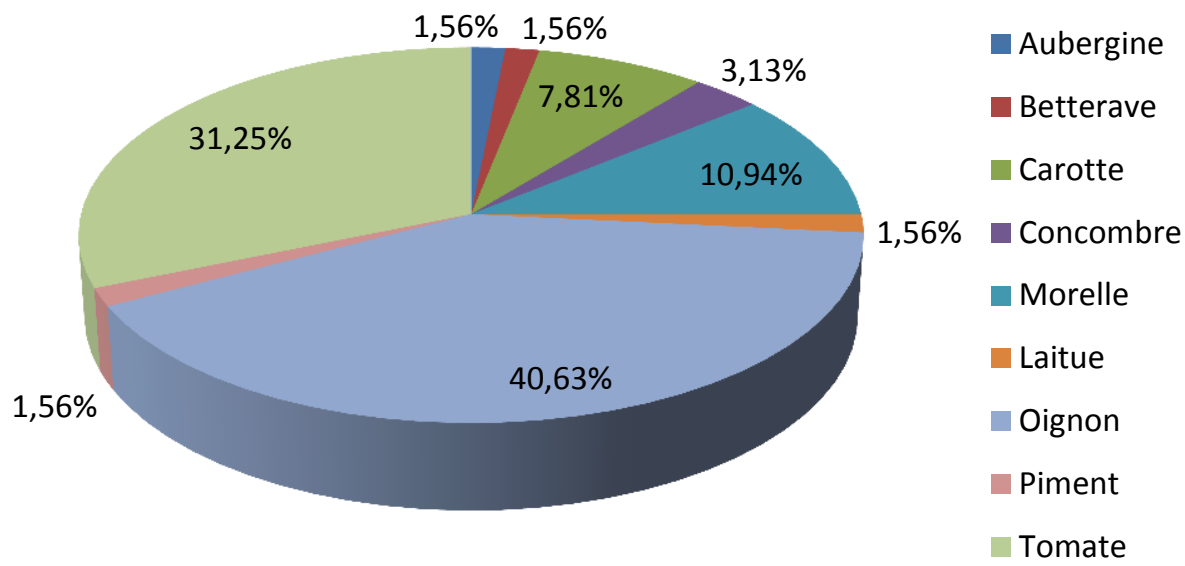

Figure 3 : Fréquence des cultures maraîchères recensées sur le site prospecté

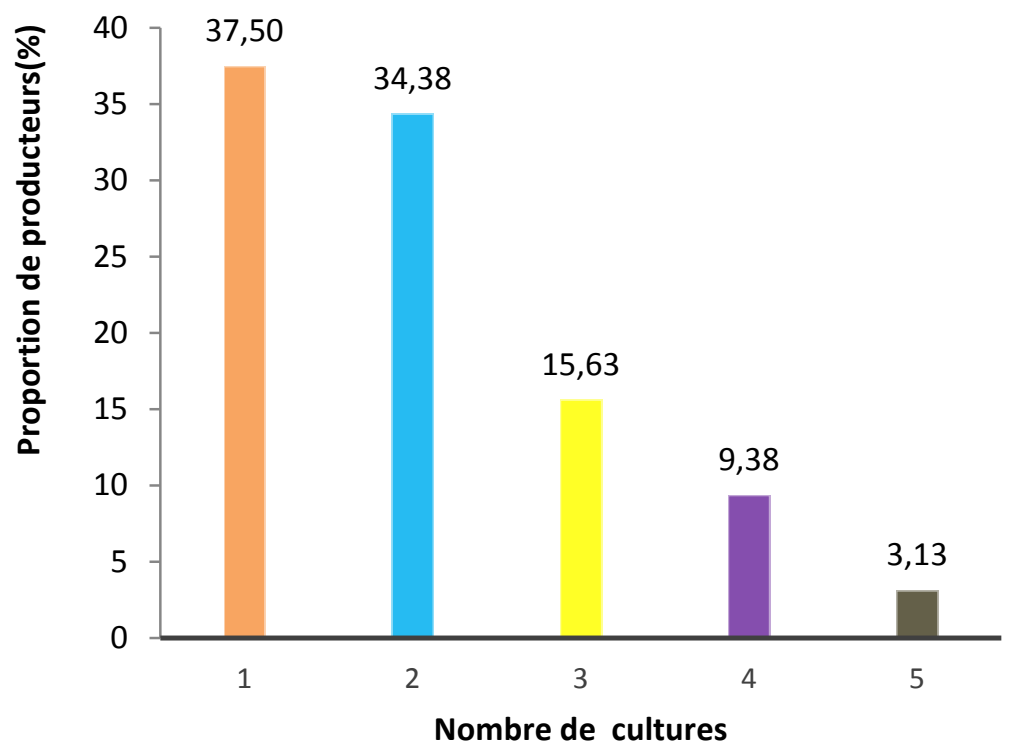

Figure 4 : Variation de nombre d'espèces cultivées par les maraîchers. 


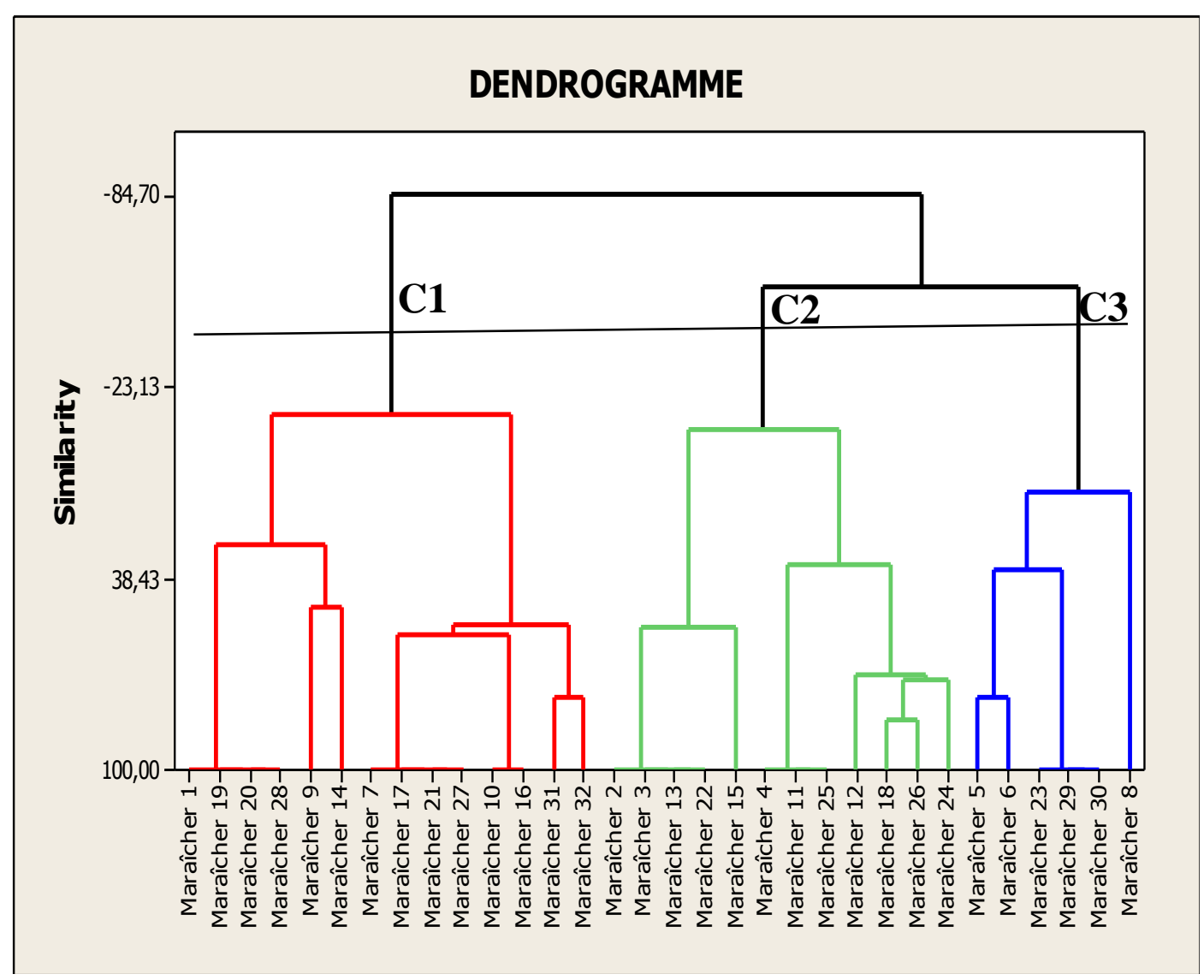

Figure 5: Dendrogramme montrant la répartition des maraîchers suivant leur similarité.

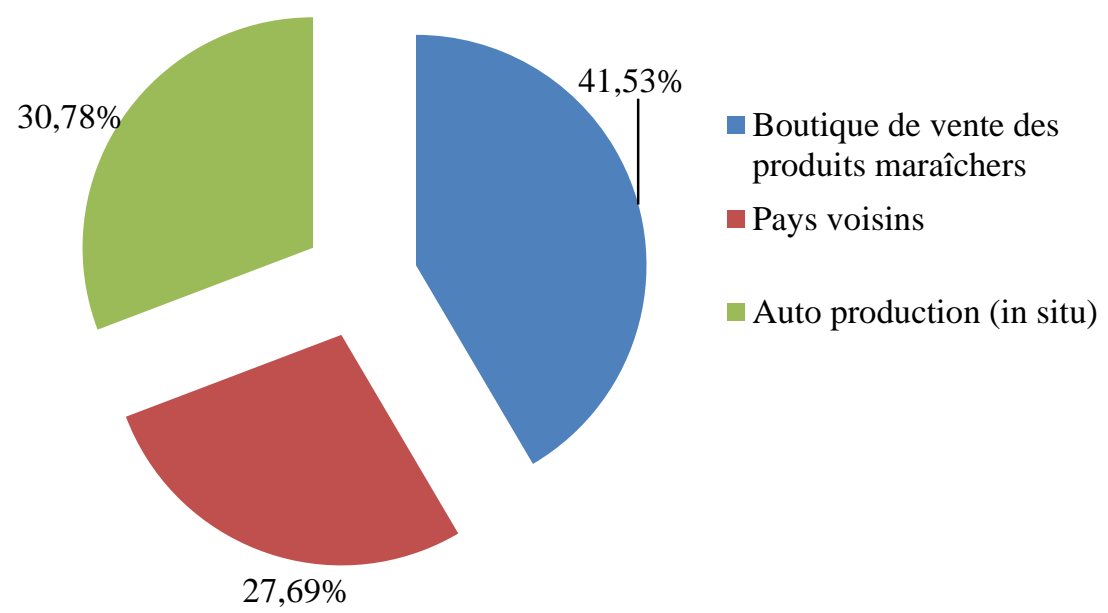

Figure 6 : Sources d'approvisionnement en semences. 
A. ADJATIN et al. / Int. J. Biol. Chem. Sci. 13(6): 2750-2764, 2019

Tableau 4 : Pratiques culturales des espèces maraîchères sur le site maraîcher de Grand-Popo.

\begin{tabular}{|c|c|c|c|c|c|c|c|c|c|}
\hline Cultures & Oignon & Tomate & Morelle & Carotte & Concombre & Betterave & Aubergine & Laitue & Piment \\
\hline Mode de semis & pépinière & pépinière & pépinière & Semis direct & Semis direct & pépinière & pépinière & pépinière & Pépinière \\
\hline Levée après semis & $7-10$ jours & $5-8$ jours & $7-8$ jours & $7-8$ jours & 4 jours & 4 jours & 5 jours & 6 jours & 7 jours \\
\hline Durée avant repiquage & $\begin{array}{l}4-6 \\
\text { semaines }\end{array}$ & $\begin{array}{l}3-4 \\
\text { semaines }\end{array}$ & 3 semaines & - & - & $\begin{array}{l}2-3 \\
\text { semaines }\end{array}$ & 2-3 semaines & 2 semaines & $\begin{array}{l}3-4 \\
\text { semaines }\end{array}$ \\
\hline Cycle de production & 3 mois & $2,5-3$ mois & 2 mois & 3 mois & 45-60 jours & 2 mois & 2 mois & 1 mois & 3 mois \\
\hline Fertilisation organique & $\begin{array}{l}1 \text { fois (1 } \\
\text { SAR) }\end{array}$ & $\begin{array}{l}1 \text { fois (1 } \\
\text { SAR) }\end{array}$ & $\begin{array}{l}1 \text { fois (1 } \\
\text { SAR) }\end{array}$ & $\begin{array}{l}1 \text { fois ( } 3 j \text { après } \\
\text { semis) }\end{array}$ & 1 fois (au semis) & $\begin{array}{l}1 \text { fois } \\
\text { (1SAR) }\end{array}$ & $\begin{array}{l}1 \text { fois } \\
\text { (1SAR) }\end{array}$ & $\begin{array}{l}1 \text { fois } \\
\text { (1SAR) }\end{array}$ & $\begin{array}{l}1 \text { fois } \\
\text { (1SAR) }\end{array}$ \\
\hline Fertilisation chimique & 3-4 fois & 2-4fois & $\begin{array}{l}\text { A chaque } \\
\text { coupe }\end{array}$ & 3fois & 3fois & 4 fois & 3fois & 4fois & 3fois \\
\hline $\begin{array}{l}\text { Traitement } \\
\text { phytosanitaire }\end{array}$ & $\begin{array}{l}\text { Tous les } 7 \\
\text { jours }\end{array}$ & $\begin{array}{l}\text { Tous les } 7 \\
\text { jours }\end{array}$ & $\begin{array}{l}\text { Tous les } 7 \\
\text { jours }\end{array}$ & $\begin{array}{l}\text { Selon le degré } \\
\text { d'attaque }\end{array}$ & Tous les 7 jours & $\begin{array}{l}\text { Tous les } 7 \\
\text { jours }\end{array}$ & $\begin{array}{l}\text { Tous les } 7 \\
\text { jours }\end{array}$ & $\begin{array}{l}\text { Tous les } 7 \\
\text { jours }\end{array}$ & $\begin{array}{l}1 \text { fois par } \\
\text { mois }\end{array}$ \\
\hline
\end{tabular}




\section{DISCUSSION}

Le maraichage constitue l'activité principale des enquêtés du site maraicher de Grand-Popo et leur génère des revenus importants. Les travaux conduits par Diao (2004) au Sénégal ont montré que l'activité maraichère constitue la principale source de revenus pour $85,23 \%$ de maraichers. La vente des produits maraîchers se fait directement sur le site de production entre les maraichers et les grossistes venant de Cotonou, du Togo et du Nigéria. Selon Kanda et al., (2009), la filière d'approvisionnement est assuré par les commerçantes grossistes qui assurent le lien entre les zones de production et les grandes villes. Ainsi le maraichage contribue ainsi au renforcement des échanges entre les centres urbains et les zones rurales. Aussi Fromageot (2005) souligne aussi que le maraichage a dynamisé les réseaux commerçants entre les campagnes des savanes soudaniennes et la ville d'Abidjan en En Côte-d'Ivoire.

La diversité des espèces cultivées est liée à la demande des consommateurs et en particulier à la grande diversité des communautés culturelles. Ces résultats sont en accord avec ceux du Sénégal (Diao, 2004) et du Cameroun (Dongmo et al., 2005). Selon certains auteurs, le mode de vie urbain s'accompagne d'une augmentation importante de la consommation de légumes et donc d'une demande croissante (Kanda et al., 2009). Cependant, dans la zone d'étude la production d'oignon occupe plus de $40 \%$ des maraichers interviewés à cause de sa grande rentabilité et ceci surtout pendant la saison des pluies. Ensuite viennent la tomate, la morelle et la carotte respectivement dans les proportions de $31,25 \% ; 10,94 \%$ et $7,81 \%$. Les autres cultures telles que le concombre, la laitue, l'aubergine, la betterave et le piment apparaissent respectivement dans les proportions de $3,13 \% ; 1,56 \% ; 1,56 \%$; $1,56 \% ; 1,56 \%$. La faible production de ces cultures (laitue, betterave, concombre et aubergine) est due au fait qu'elles ne sont majoritairement demandées que pendant les périodes de fête. La faible proportion de certaines cultures s'explique par le fait qu'il s'agit des cultures de contre saison. En effet, le rang occupé par chacune des cultures varie en fonction de la période de l'année. De plus, le type et le nombre de spéculations varient d'un producteur à un autre en fonction des moyens financiers et de l'accès à la terre..

Compte tenu de l'état de pauvreté des sols (sols sableux) de la zone d'étude, l'utilisation des intrants est nécessaire pour la production des cultures maraîchères (Lawani et al., 2005). Cependant, les intrants contribuent à la pollution des eaux souterraines qui ne sont qu'à environ 5 à $7 \mathrm{~m}$ par rapport à la surface des sols, à la pollution des sols et à la dégradation des plantes (Lawani et al., 2005). Les engrais minéraux et organiques contiennent des nitrates qui sont des composés chimiques faits d'azote et de l'oxygène qui se trouvent à l'état naturel dans certains légumes, dans le sol et dans les viandes. Selon le même auteur, la quantité de nitrates disponibles dans le sol est le principal facteur limitant la croissance des plantes.

Les contraintes majeures qui entravent la production maraîchère sont prioritairement les insectes, les nématodes et les agents pathogènes dont les champignons. Pour faire face à ces exigences et améliorer la productivité et le rendement de leurs cultures, les maraichers font recours à l'usage des pesticides chimiques. Au total, quatorze (14) pesticides ont été répertoriés parmi lesquels les insecticides se retrouvent en bonne place avec $56,25 \%$ de réponses). Ces résultats sont similaires à ceux obtenus au Togo par Kanda et al. (2009) qui rapportent que $56 \%$ des vingt-sept (27) pesticides recensés sont des insecticides ; ce qui confirme la prédominance des insectes parmi les ravageurs des cultures maraichères et de l'agriculture non seulement au Bénin mais aussi dans la sous-région en Afrique de l'ouest. L'efficacité immédiate des pesticides de synthèse fait oublier aux 
producteurs les risques sanitaires tels que l'irritation cutanée, les maux de tête, la toux, le vertige, les troubles respiratoires, la fatigue, la diarrhée associés à leur utilisation (Kanda et al., 2009 ; Ahouangninou et al., 2011). Par conséquent, très peu de pesticides de type biologique ont été enregistrés. Le même constat est fait au Togo où très peu de maraichers utilisent des bio-pesticides bien que ces produits se soient révélés efficaces et peu toxiques (Kanda et al., 2009). Les principales raisons limitant l'utilisation des bio-pesticides et les extraits de plantes sont entre autres, l'insuffisance d'information sur leur efficacité, leur non disponibilité, la lenteur de leur action, la grande superficie des périmètres maraichers, la complexité de leur préparation, leur durée d'efficacité, leur spécificité aux ravageurs et leur prix d'achat plus élevés que celui des pesticides chimiques (Chouti et al., 2018). L'utilisation abusive des produits phytosanitaires constitue encore une source d'intoxication et de contamination de l'environnement ainsi que de la chaine trophique avec la conséquence néfaste sur la vie humaine (Mougeot, 2000). Selon Amoatey et Acquah (2010), la combinaison de certaines pratiques agricoles comme la rotation des cultures, la protection physique (filets antiinsectes), l'utilisation des plantes pesticides (toute plante dont les propriétés chimiques pourraient être exploitées pour lutter contre les organismes considérés comme nuisibles) et par conséquent susceptibles de réduire significativement la pression des bioagresseurs et le besoin en pesticides de synthèse. Les produits naturels issus des plantes peuvent aussi permettre d'accroître les rendements avec un rapport cout/bénéfice comparable à celui des pesticides de synthèse (Amoabeng et al., 2014). Aussi les différentes contraintes doivent être prises en compte dans le développement des programmes de sélection et d'amélioration variétale des ressources génétiques des différentes spéculations recensées sur le site prospecté ou des programmes d'insertion d'autres spéculations du secteur maraicher tenant compte des conditions climatiques du milieu (Gbaguidi et al., 2013).

\section{Conclusion}

Ce travail a permis d'inventorier les espèces maraîchères cultivées sur le site maraîcher de Grand-Popo et d'identifier les contraintes de production. La production des cultures maraîchères est dominée par les légumes-fruits et assure non seulement la sécurité alimentaire mais constitue aussi une source de revenus à la population. Cependant, elle est confrontée à certaines difficultés dont les principales sont les attaques des insectes, nématodes et les champignons. La lutte chimique reste la méthode la plus pratiquée pour lutter contre ces ravageurs. Pour la promotion des cultures maraîchères et pour permettre à l'agriculture urbaine ou périurbaine d'atteindre ses objectifs, il est important d'agir sur ces contraintes. Aussi, est-il nécessaire de créer de nouvelles variétés en tenant compte aussi bien du rendement que des qualités organoleptiques sans oublier leur adaptation aux nouvelles conditions climatiques.

\section{CONFLIT D'INTERETS}

Les auteurs ne déclarent aucun conflit d'intérêts.

\section{CONTRIBUTIONS DES AUTEURS}

AA a co-supervisé les enquêtes sur le terrain, pris part à la rédaction et la correction et approuvé la version finale du manuscrit. $\mathrm{BA}$ a rédigé le questionnaire, mené les enquêtes auprès des ménages, pris part à la rédaction du manuscrit. BZ s'est occupé des analyses statistiques et a approuvé la version finale du manuscrit. YH a procédé à l'identification des espèces végétales, pris part à la rédaction et approuvé la version finale du manuscrit. DA a développé le concept de 
l'étude, et a approuvé la version finale du manuscrit.

\section{REFERENCES}

Adomou AC. 2005. Vegetation patterns and environmental gradients in Benin: Implications for biogeography and conservation. PhD. thesis, Wageningen University the Netherlands, $136 \mathrm{p}$.

Agossou G, Ahouansou T, Assogba-Komlan F. 2001. Étude sur la promotion de la filière des cultures maraîchères au Bénin, Rapport principal, PCM/INRAB/MAEP, $87 \mathrm{p}$.

Amoatey CA, Acquah E. 2010. Basil (Ocimum basilicum) intercrops as a pest management tool in okra cultivation in the Accra Plains. Ghana Journal of Horticulture, 8 : 65-70.

Diao MB. 2004. Situation et contraintes des systèmes périurbaiins de production horticole et animale dans la région de Dakar. Cahier Agricultures, 13 :39-49.

Agueh V, Degbey CC, Sossa-Jerome C, Adomahou D, Paraiso MN, Vissoh S, Makoutode M, Fayomi B. 2015. Niveau de contamination des produits maraîchers par les substances toxiques sur le site de Houéyiho au Bénin. Int. J. Biol. Chem. Sci., 9 (1): 542-551.

Ahouangninou C, Fayomi EB, Martin T. 2011. Évaluation des risques sanitaires et environnementaux des pratiques phytosanitaires des producteurs maraichers dans la commune rurale de Tori-Bossito (Sud-Bénin). Cah. Agric., 20 (3): 216-222.

Amoabeng BW, Gurr GM, Gitau CW, Stevenson PC. 2014. Cost benefit analysis of botanical insecticide use in cabbage: implications for smallholder farmers in developing countries. Crop Prot., 57: 71-76.

Atidegla SC, Agbossou EK, Huat J, Glele Kakai R. 2011.Contamination métallique des légumes des périmètres maraîchers urbains et péri urbains : Cas de la commune de Grand-Popo au Bénin. Int. J. Biol. Chem. Sci., 5 (6): 2351-2361.

Atidegla SC, Koumassi HD, Houssou ES. 2017. Variabilité climatique et production maraîchère dans la plaine inondable d'Ahomey-Gblon au Bénin. Int. J. Biol. Chem. Sci., 11(5): 22542269.

Chouti WK, Adanve M, Mama D. 2018. Dosage Du plomb et du zinc dans les cultures de l'amarante (Amarantus cruentus) et de la Grande morelle (Solanum macrocarpum): cas de quelques sites maraîchers de PortoNovo. Int. J. Biol. Chem. Sci., 12 (5): 2381-2395.

Dongmo TJ, Gockowski S, Hernandez LDK, Awono R, Mbang M. 2005. L'agriculture périurbaine à Yaoundé : ses rapports avec la réduction de la pauvreté, le développement économique, la conservation de la biodiversité et de l'environnement.

Tropicultura, 23(3): 130-135.

FAO. 2012. Growing greener cities in Africa. First status report on urban and periurban horticulture in Africa. Roma: FAO.

Fromageot A. 2005. Dépasser l'enclavement : le maraîchage des savanes et l'approvisionnement d'Abidjan. Espaces Populations Sociétés, 1 : 83-98.

Gbaguidi AA, Dansi A, Loko LY, Dansi M, Sanni A. 2013. Diversity and agronomic performances of the cowpea (Vigna unguiculata Walp.) landraces in Southern Benin. International Research Journal of Agricultural Science and Soil Science, 3(4): 121-133.

Houssou SE. 2014. Variabilité climatique et production maraîchère dans le bas-fond de Houinga-Houégbé (Commune de Houéyogbé). Mémoire de Master II, FSA/UAC, p 119. 
Kanda M, Akpavi S, Wala K. 2014. Diversité des espèces cultivées et contraintes à la production en agriculture maraichère au Togo. Int. J. Biol. Chem. Sci., 8(1) : 115127.

Kanda M. 2009. Le maraichage périurbain à Lomé : pratiques culturales, risques sanitaires et dynamiques spatiales. Cah. Agric., 18(4) : 356-363.

Koc MR, Macrae JAL, Welsh J. 2006. Armer les Villes contre la Faim: Systèmes Alimentaires Urbains Durables. CRDI : Canada ; 243 p.

Lawani M, Lawani L, Akakpo A, Déguénon S. 2005. Rapport sur la reconnaissance pédologique sur le Littoral à GrandPopo. Centre National d'Agro-pédologie, Abomey-Calavi, Bénin, p.26.

Mondédji AD. 2015. Analyse de quelques aspects $\mathrm{du}$ système de production légumière et perception des producteurs de l'utilisation d'extraits botaniques dans la gestion des insectes ravageurs des cultures maraichères au Sud du Togo. Int. J. Biol. Chem. Sci., 9(1): 98-107.

Mougeot LJA. 2000. Urban agriculture: definition, presence, potential and risks. In Growing cities, growing food: urban agriculture on the policy agenda, a reader on urban agriculture. Bakker $\mathrm{N}$,
Dubbeling M, Gündel S, SabelKoschella U, de Zeeuw H, (eds). Feldafing, Allemagne, Des/Etc, 123-142. Pan-Africa. 2005. Pesticides et alternatives. Bulletin PAN-Africa, 26 : 3-5.

Tchabi Vincent Isidore, Azocli David, Biaou Gilbert D. 2012. Effet de différentes doses de bouse de vache sur le rendement de la laitue (Lactuca sativa L.) à Tchatchou au Bénin. Int. J. Biol. Chem. Sci., 6(6): 5078-5084.

Tiamiyou I, Sodjinou E. 2003. Étude diagnostic des filières maraîchères de la vallée du fleuve Niger. Rapport provisoire, PADSE-CAD/FSA/UACMAEP, $89 \mathrm{p}$.

Yarou BB, Silvie P, Assogba-Komlan F, Mensah A, Alabi T, Verheggen F, Francis F. 2017. Plantes pesticides et protection des cultures maraichères en Afrique de l'Ouest (synthèse bibliographique). Biotechnol. Agron. Soc. Environ., 21(4) : 288-304.

Yolou Fi, Yabi I, Kombieni F, Tovihoudji Pg, Yabi Ja, Paraïso Aa, Afouda F. 2015. Maraichage en milieu urbain à Parakou au Nord-Bénin et sa rentabilité économique. Int. J. Innovation Sci. Res., 19 (2) : 290-302. 